\title{
CORRESPONDENCE
}

\section{Collaborations span 1,553 kilometres}

Global communications are making physical distances between research collaborators ever more irrelevant. Our analysis of 39 million authors' addresses in research publications indexed in Thomson Reuters' Web of Science for 1980-2009 reveals some surprising exceptions to this trend.

We found that collaboration in the natural sciences over this period spanned the longest distances, with the medical and life sciences catching up fast. Collaboration was most confined for the social sciences and humanities, but this too has been extending rapidly over the past decade. Overall, the average collaboration distance increased more or less linearly from 334 kilometres in 1980 to $1,553 \mathrm{~km}$ in 2009.

Countries in the Southern Hemisphere, such as New Zealand and Australia, and several developing countries in the tropics contributed to some of the higher scores. Turkey, Iran, India and most eastern European countries are among the least globalized in terms of long-distance scientific collaboration. Surprisingly, some of the countries with rapid growth in scientific-publication output, such as China and Brazil, show hardly any increase in globalization, or even a slight decrease.

Researchers are in a better position than ever before to engage in long-distance collaborations. This, combined with the increasingly dispersed location of research centres across the globe, could account for the $5.4 \%$ annual growth in collaboration distances.

Robert J. W. Tijssen, Ludo Waltman and Nees Jan van Eck Centre for Science and Technology Studies (CWTS), Leiden
University, the Netherlands. tijssen@cwts.leidenuniv.nl

\section{Open up monitoring of deep-sea drilling}

We need independent monitoring of the hydrocarbon industry's deep-sea activities to widen understanding of their potential impact (Nature 472, 152-154; 2011).

The facilities for this monitoring already exist. Realtime observatory systems that deliver data from the sea floor and water column over the Internet can be combined with sample collection and impact assessments of the marine industry to help untangle natural from anthropogenic changes and aid sustainable use of resources.

Efforts such as the European Seas Observatory NETwork, the European Multidisciplinary Seafloor Observatory and Ocean Networks Canada are enabling remote observing, early warning, data discovery and archiving. Researchers are also working with industry, for example on the Deep-ocean Environmental Long-term Observatory System project.

With the United Nations, the intergovernmental Group on Earth Observations - the body coordinating the set up of a Global Earth Observation System of Systems (GEOSS) could advance these initiatives and disseminate agreed terms to stakeholders.

Public availability of such collective data would also aid mitigation and make an important contribution to GEOSS.

Henry A. Ruhl National

Oceanography Centre,

Southampton, UK.

h.ruhl@noc.ac.uk

Imants G. Priede Oceanlab, University of Aberdeen, UK. Competing financial interests: declared (see http://dx.doi. org/10.1038/473154b for details).

\section{Modernize Ukraine's university system}

Twenty years after independence, the Ukrainian government is trying to stay competitive in scientific areas such as aerospace, applied mathematics, theoretical physics, energy and organic farming. But its higher education is still tied to the old Soviet system.

The government's intended reforms do not go far enough towards meeting international standards. For example, Ukrainian scientists are trained for a Soviet-style Doctor of Sciences (DSc) degree, which is not based on original research or external peer review. Scholars instead spend $10-20$ years on unproductive, essentially bureaucratic work. Therefore, despite a doubling in the number of DSc students over the past 20 years (see go.nature. com/f8agxb), international ratings for Ukrainian universities have remained low.

A paucity of publications in international peer-reviewed journals also stems from Ukraine's academic promotion system, which fosters inertia among research scientists, and from poorly developed skills in foreign languages.

Ukraine's universities need to adopt internationally recognized standards, promote autonomy under democratic and competent management, and support academics to encourage them to stay at home.

Alexander Gorobets Sebastopol National Technical University, Ukraine.

alex-gorobets@mail.ru

Tracking China's publication boom

The 2010 Asia-Pacific Publishing Index of the Nature Publishing Group (NPG) family of

journals (go.nature.com/ fqm8s3) analyses publication growth and research trends in this important and dynamic region. But omission of a crucial component of the analysis may have distorted its performance comparisons between countries

The documented increase in NPG publications in the region for 2000-10 does not take into account the increase over that period in the number of articles per journal per year (see Scopus bibliographic database; www. scopus.com) or the rise in the number of NPG journals (from 7 to 17$)$.

Comparing the percentage publication share of Japan and China in NPG journals between 2000-10 reveals that Japan's barely changed (increasing from $7.5 \%$ to about $9.5 \%$ ). China's grew much faster (from $0.6 \%$ to $5 \%$ ) over the period, indicative of a vibrant and expanding research community.

This picture is very different from the results presented in the supplement.

Thomas S. Jones, Andrew M. Plume Elsevier, Kidlington, Oxford, UK.

a.plume@elsevier.com

Publisher's note: We noted in the supplement's introduction that removing the effects of the new publication Nature Communications reduced the growth in papers from the Asia-Pacific region from $25.4 \%$ to $14.6 \%$. We stand by our conclusion that growth in the number of NPG papers over that period for Japan was modest and spectacular for China.

CONTRIBUTIONS

Correspondence may be sent to correspondence@ nature.com after consulting the guidelines at go.nature. com/cmchno. Readers are welcome to comment online at www.nature.com/nature. 